\title{
Statistical Approach in Analyzing of Advanced Metering Data in Power Distribution Grid
}

\author{
Ivan Ramljak, Member, IEEE, and Drago Bago, Member, IEEE
}

\begin{abstract}
In last period many distribution system operators (DSO) invest significant amount of money in smart metering system. Those investments are in part due to regulatory obligations and in part due to needs of DSO (utilities) for knowledge about electric energy consumption. Term - electric energy consumption, refers not only on real consumption of electric energy but also on data about peak power, unbalance, voltage profiles, power losses etc. Data which DSO can obtain from smart meters depend on type of smart metering system. Further, smart meters as source of data can be implemented in transformer stations (TS) MV/LV and in LV grid at consumer level. Generally, smart meters can be placed in any node of distribution grid. As amount of smart meters is greater, the possibility of data analysis is greater. In this paper a smart metering system of J.P Elektroprivreda HZ HB d.d, Mostar, Bosnia and Herzegovina will be presented. One statistical approach for analyzing of advanced metering data of TS MV/LV will be presented. Statistical approach presented here is powerful tool for analyzing great amount of data from distribution grid in simple way. For example, transformer in TS MV/LV can be overloaded for $30 \%$, but overload period can be for example single one-hour period in whole year. With smart meter data, false conclusions can be avoided. In concerned case, grid operation engineer will not make decision of transformer replacing. With knowledge of only max. power of transformer (without time series data), false conclusion can be adopted about transformer replacing. This can increase costs of grid operation for DSO. Smart metering can help in transformer monitoring. Voltage drop in LV buses of TS MV/LV can be $10 \%$ for example. It means that quick intervention in grid must be performed. But, period of increased voltage drop can be only single one-hour period in whole year (for example). On other side, TS MV/LV can have voltage drop of $7 \%$ for example in halfyear period. These data, obtained by smart meters, can help in issuing of priority grid investments. Main contribution of this paper is in performing of the statistical analysis of smart meter data in distribution grid and using the obtained results in maintenance/investment planning process.
\end{abstract}

Index Terms-distribution grid, smart metering, statistical analysis.

\section{INTRODUCTION}

In this paper, benefits of using statistics in smart meter data analyzing will be analyzed (for power distribution grid). Rather, data of smart meters placed in MV/LV transformer stations (TS) will be analyzed. This paper is extended version

Manuscript received January 9, 2019; revised March 25, 2019. Date of publication April 5, 2019. Date of current version June 3, 2019.

Authors are with the Development Department of Public Electric Company "'Elektroprivreda HZHB', Mostar, BiH (e-mails: ivan.ramljak@ephzhb.ba, drago.bago@ephzhb.ba).

Digital Object Identifier (DOI): 10.24138/jcomss.v15i2.683 of paper originally presented at Conference SpliTech 2018 [1]. Utilization of smart metering data can be diverse. It is primary used in load profiling [2]. Using smart metering data loads can be divided in groups, subgroups etc. Different profile types can be specified: houses, agriculture, industry etc. Load profile can be introduced for specified day, week, season etc. These data obtained for one region can be projected on other similar region [2]. According to [3], smart meter data can be used for identification in grid operation. It is also usable for grid control. In [3], correlation and autocorrelation analysis among smart meter data is introduced. Distribution grid analysis accuracy can be improved using smart meter data [4]. Modeling of distribution feeder using smart metering data is presented in [5]. It is concluded that smart metering data improves distribution grid model accuracy. Smart utilization of smart meter data presents opportunity for utilities to enhance savings, customer service and energy efficiency improving [6]. Distribution grid can be more flexible, efficient and reliable using smart metering data. If smart metering data are not used properly, they can make congestion in communication network and waste data storage capability. Only properly used smart metering data can help DSO planers in making distribution grid economical and thus potential profitable. In [7] and [8] is explained benchmarking of smart meter data analytics. In [9] - [11] are presented clustering techniques for smart meter data analysis. Using clustering, customer loads with similar profiles can be identified. It is used in consumers monitoring and analyzing. [9]. In [11] is stated that is hard to identify individual clusters. Opposite this below, this paper presents one new statistical approach for smart meter data analysis. Advanced metering system in "Elektroprivreda HZ HB" is presented in Fig. 1.

Smart meters are located in TS MV/LV and in some consumers. Every year number of consumers with smart meter increases. This paper focuses on advanced metering data in TS MV/LV. Location of those smart meters is shown in Fig. 2. Historically, smart meters were first placed in TS and after that they are placing continuously at consumers.

First in line are great industry consumers and later houses. Generally, smart meters have improved following:

- Remote reading system improved accuracy and reduced errors in reading compared to human. Reading costs are significant less (link to Billing).

- Limiting peak power of consumers. Increasing income from increasing of consumer peak power. 
- Load profile characteristic.

- Identification (reduction) of technical and nontechnical losses.

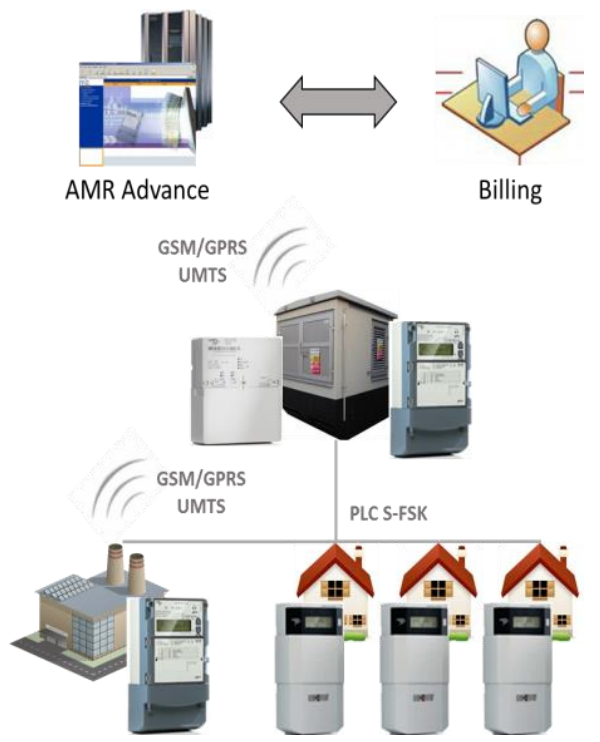

Fig. 1. Advanced metering system in "Elektroprivreda HZ HB”, Mostar [1]

Smart meters located in TS MV/LV can give information about electric energy (consumed, generated), power P and Q, cos fi, frequency, voltage and current. Time period of collected data can be: 1 min., 5 min., 10 min., 15 min., 20 min., 30 min., $60 \mathrm{~min}$. As elected time period is shorter data listing lasts longer. When we talk about communication technologies, GSM/GPRS (UMTS today) is used for communication between meters and server (through provider of mobile communications services) - Fig. 1. GSM/GPRS technology is with good performances, fast, reliable and it has great traffic data potential. Communication protocol is TCP/IP. PLC S-FSK (Power Line Carrier Spread Frequency Shift Keying) communication technology is in use at communication level consumer-TS (Fig. 1). It is communication through LV grid. It is less reliable than GPS/GPRS communication but it is cheaper and it is proved as good choice in this case.

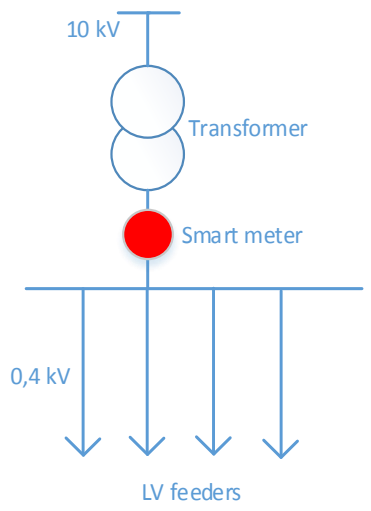

Fig. 2. Location of smart meters in MV/LV TS [1]

Data provided by AMR Advance software for data analysis can easy be transferred in .xls extension for further analysis.
Smart meter data analyzing in literature is so far usually used in load profile clustering [9-11]. Besides that, smart metering is used in distribution feeder modeling and distribution grid analysis improving.

Statistics in smart meter data analysis as powerful tool will be presented in this paper. Using statistics in smart meter data analysis, utilities can obtain relevant information about loads, losses, voltage profiles etc., what can be helpful in reconstruction/investment priorities planning.

Statistical approach brings wider scope of smart meter data utilization. The main objectives of smart meter data utilization, presented in this paper, are as follows:

- Statistical approach authentication in smart meter data analyzing.

- Utilization of statistics results in distribution grid management.

- Practical case studies.

For example, knowing load profiles and considering rated power of transformers, replacing and rotating of transformers can be planned. It can be helpful in order of reducing technical losses. On other side, knowing voltage profiles of TS and using statistics, priorities in improving voltage conditions in distribution grid can be determined. Priorities can be very important fact for utilities considering possible financial restrictions in investment/reconstructions of distribution grid planning.

\section{StATISTICAL ANALYZING}

\section{A. Descriptive Statistics}

Data provided by AMR Advance software and transferred in xls extension can have large amount. Those data can be hard to understand and thereby conclusions about those data can be unclear and incorrect. Advanced analyzing of those data can be implemented using statistical tools.

Basic descriptive statistics calculations are presented below. Descriptive statistics gives primary and important information about data time series.

Arithmetic mean is calculated by:

$$
\bar{x}=\frac{\sum_{i=1}^{k} f_{i} x_{i}}{\sum_{i=1}^{k} f_{i}}
$$

where $f_{i}$ presents frequency of $x_{i}$ and $k$ number of frequencies.

Variance is calculated by:

$$
\sigma^{2}=\frac{\sum_{i=1}^{k} f_{i} x_{i}^{2}}{\sum_{i=1}^{k} f_{i}}-\bar{x}^{2}
$$

Standard deviation is then square root of variance. 
Skewness is defined with:

$$
\alpha_{3}=\frac{\mu_{3}}{\sigma^{3}}
$$

where:

$$
\mu_{3}=\frac{\sum_{i=1}^{k} f_{i}\left(x_{i}-\bar{x}\right)^{3}}{\sum_{i=1}^{k} f_{i}}
$$

If skewness is zero, distribution of data is symmetric. If skewness is closer to +2 , distribution of data has positive skew. If skewness is closer to -2 , distribution of data has negative skew.

The aim of statistical analysis was to analyze two sets of data from smart meters:

- Transformer power (load values) in percentage of rated power for two TS (A, B) was analyzed. This analyze is in order to consider load values in time series characteristics.

- $\quad$ Per-unit (p.u) voltage (ratio of actual voltage value and base value of voltage) for two TS (C, D) was analyzed. This analyze is in order to consider voltage drop in time series characteristics.

TS A is rural TS with $100 \mathrm{kVA}$ rated power of transformer, and fed with $\mathrm{Al} / \mathrm{Fe}$ conductors.

TS B is industrial TS with $1000 \mathrm{kVA}$ rated power, fed with XHE cable.

TS C and D are rural TS, both at the different end side of long radial overhead line in rural area (line with $\mathrm{Al} / \mathrm{Fe}$ conductors).

All TS are fed from MV grid, rated voltage $10 \mathrm{kV}$.

Table I shows basic descriptive statistics parameters of load values in percentage (\%) of transformer rated power.

Table II shows basic descriptive statistics parameters of voltage values (p.u)

Time series from advanced metering system were 60 minute intervals in all cases.

TABLE I.

Basic Data of LoAd VALUES in Percentage of RATEd TRANSFORMER POWER (\%) [1]

\begin{tabular}{ccc}
\hline \hline $\begin{array}{c}\text { Transformer } \\
\text { station }\end{array}$ & $\mathrm{A}$ & $\mathrm{B}$ \\
\hline mean & 49.007 & 19.700 \\
median & 47.500 & 18.250 \\
std. deviation & 17.137 & 11.274 \\
skewness & 0.718 & 0.759 \\
min. value & 2.5 & 0.25 \\
max. value & 132.5 & 64.25 \\
\hline \hline
\end{tabular}

\section{B. Statistical Modeling Approach}

Some statistical approach ideas in power system analysis can be found in [12] - [18]. In [12, 13], distribution system reliability analysis is presented probabilistic. In [14, 15], residential load values in distribution grid are presented with statistical approach. Beta distribution is introduced in reliability analysis in [16]. In [17], statistics is used in analyzing conductor clashing particles. A statistical analysis of energy losses determination is presented in [18]. Probability distributions can be viewed as a powerful tool for dealing with uncertainty. The goal was to select theoretical distributions to describe the frequency of transformer load values and p.u voltages for selected TS. Several distributions were fitted: Normal, Beta, Gamma and Log-Pearson 3 probability density functions (PDF). Their mathematical description is given in Table III.

TABLE II.

Basic Data of P.U Voltage Values (P.U) [1]

\begin{tabular}{ccc}
\hline \hline $\begin{array}{c}\text { Transformer } \\
\text { station }\end{array}$ & $\mathrm{C}$ & $\mathrm{D}$ \\
\hline mean & 0.932 & 0.942 \\
median & 0.935 & 0.945 \\
std. deviation & 0.011 & 0.010 \\
skewness & -0.359 & -0.276 \\
min. value & 0.865 & 0.885 \\
max. value & 0.965 & 0.975 \\
\hline \hline
\end{tabular}

\section{Statistical Modeling Approach}

Some statistical approach ideas in power system analysis can be found in [12] - [18]. In [12, 13], distribution system reliability analysis is presented probabilistic. In [14, 15], residential load values in distribution grid are presented with statistical approach. Beta distribution is introduced in reliability analysis in [16]. In [17], statistics is used in analyzing conductor clashing particles. A statistical analysis of energy losses determination is presented in [18]. Probability distributions can be viewed as a powerful tool for dealing with uncertainty. The goal was to select theoretical distributions to describe the frequency of transformer load values and p.u voltages for selected TS. Several distributions were fitted: Normal, Beta, Gamma and Log-Pearson 3 probability density functions (PDF). Their mathematical description is given in Table III.

First three of them are two-parameter distributions and forth is three-parameter distributions.

Some statistical tests are usually used to decide if a sample comes from a hypothesized continuous distribution. Those tests are: Chi-squared test, Kolmogorov-Smirnov test and AndersonDarling test.

It will be shown that all four distributions are good fitted. Kolmogorov-Smirnov test is based on difference between the theoretical and the empirical cumulative distribution function (CDF). Chi-squared test is based on differences between empirical and theoretical frequencies. Anderson-Darling test gives more weight to the tails than Kolmogorov-Smirnov test, what is less important in this case. Kolmogorov-Smirnov test is relevant test for this purpose since finally, CDF is used in calculations.

Kolmogorov-Smirnov test is used to decide if a sample comes from a hypothesized continuous distribution. It is based on the empirical cumulative distribution function (ECDF). Assume that there is a random sample $x_{1}, \ldots, x_{\mathrm{n}}$ from some distribution with cumulative distribution function $\mathrm{CDF} F(x)$.

The empirical CDF is denoted by:

$$
F_{n}(x)=\frac{1}{n}[\text { Numberof observation } \leq x]
$$


TABLE III.

MATHEMATICAL DESCRIPTION OF DisTRIBUTIONS [1]

\begin{tabular}{|c|c|c|c|}
\hline Name & PDF & CDF & Limits \\
\hline Normal & $\frac{e^{\left(-\frac{1}{2}\left(\frac{x-\mu}{\sigma}\right)^{2}\right)}}{\sigma \sqrt{2 \pi}}$ & $\begin{array}{c}\Phi\left(\frac{x-\mu}{\sigma}\right), \\
\Phi(x)=\frac{1}{2 \pi} \int_{0}^{x} e^{-\frac{t^{2}}{2}} \\
\text { - Laplace } \\
\text { Integral }\end{array}$ & $\begin{array}{c}-\infty<x<\infty \\
\sigma>0\end{array}$ \\
\hline Beta & $\begin{array}{c}\frac{1}{B\left(\alpha_{1}, \alpha_{2}\right)} \frac{(x-a)^{\alpha_{1}-1}(b-x)^{\alpha_{2}-1}}{(b-a)^{\alpha_{1}+\alpha_{2}-1}} \\
B\left(\alpha_{1}, \alpha_{2}\right)=\int_{0}^{1} t^{\alpha_{1}-1}(1-t)^{\alpha_{2}-1} d t \\
- \\
\text { Beta Function } \\
B\left(\alpha_{1}, \alpha_{2}\right)=\int_{0}^{x} t^{\alpha_{1}-1}(1-t)^{\alpha_{2}-1} d t \\
\text { - Incomplete Beta Function } \\
0 \leq x \leq 1\end{array}$ & $\begin{array}{c}I_{z}\left(\alpha_{1}, \alpha_{2}\right), \\
z \equiv \frac{x-a}{b-a} \\
I_{z}=\frac{B_{x}\left(\alpha_{1}, \alpha_{2}\right)}{B\left(\alpha_{1}, \alpha_{2}\right)} \\
\text { - Regularized } \\
\text { Incomplete } \\
\text { Beta Function }\end{array}$ & $\begin{array}{c}a \leq x \leq b \\
\alpha_{1}>0 \\
\alpha_{2}>0 \\
a<b\end{array}$ \\
\hline Gama & $\begin{array}{c}\frac{x^{\alpha-1}}{\beta^{\alpha} \Gamma(\alpha)} e^{\frac{-x}{\beta}} \\
\Gamma(\alpha)=\int_{0}^{\infty} t^{\alpha-1} e^{-t} d t- \\
\text { Gama Function } \\
\Gamma_{x}(\alpha)=\int_{0}^{x} t^{\alpha-1} e^{-t} d t- \\
\text { Incomplete Gama Function }\end{array}$ & $\frac{\Gamma_{\frac{x}{\beta}}(\alpha)}{\Gamma(\alpha)}$ & $\begin{array}{c}0<x<\infty \\
\alpha>0 \\
\beta>0\end{array}$ \\
\hline $\begin{array}{c}\text { Log } \\
\text { Pearson } \\
3\end{array}$ & $\frac{1}{x|\beta| \Gamma(\alpha)}\left(\frac{\ln (x)-\gamma}{\beta}\right)^{\alpha-1} e^{\left(-\frac{\ln (x)-\gamma}{\beta}\right)}$ & $\frac{\frac{\Gamma(\ln (x)-\gamma)}{\beta}^{(\alpha)}}{\Gamma(\alpha)}$ & $\begin{array}{c}0<x<e^{\gamma} \\
\beta<0 \\
e^{\gamma}<x<\infty \\
\alpha>0 \\
\beta>0 \\
\beta \neq 0\end{array}$ \\
\hline
\end{tabular}

testing whether a data set is from a completely specified distribution. If one or more distribution parameters are estimated, the results will be conservative: the actual significance level will be smaller than that given by the standard tables, and the probability that the fit will be rejected in error will be lower.

Goodness of Fit of chosen distributions is verified using EasyFit software [19]. EasyFit displays the P-values based on the Kolmogorov-Smirnov test statistics (D) calculated for each fitted distribution. The P-value, in contrast to fixed values, is calculated based on the test statistic, and denotes the threshold value of the significance level in the sense that the null hypothesis $\left(\mathrm{H}_{0}\right)$ will be accepted for all values of less than the $\mathrm{P}$-value. For example, if $\mathrm{P}=0.025$, the null hypothesis will be accepted at all significance levels less than $P$ (i.e. 0.01 and 0.02 ), and rejected at higher levels, including 0.05 and 0.1 ).

Fig. 3. presents general CDF for statistical analysis presented in this paper.

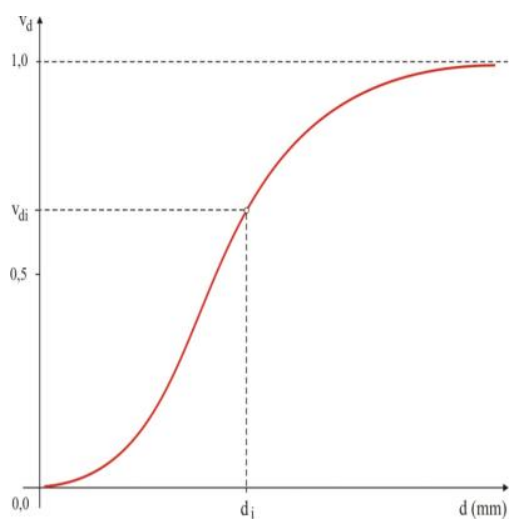

Fig. 3. General CDF for statistical analysis [1]

CDF is given by:

$$
F_{d}(d)=\int_{0}^{d} f(d) d d
$$

where PDF is $f(d)$.

The Kolmogorov-Smirnov statistic (D) is based on the largest vertical difference between the theoretical and the empirical cumulative distribution function:

$$
D=\max _{1 \leq i \leq n}\left(F\left(x_{i}\right)-\frac{i-1}{n}, \frac{i}{n}-F\left(x_{i}\right)\right)
$$

The null and the alternative hypotheses are:

- $\mathrm{H}_{0}$ : the data follow the specified distribution;

- $\mathrm{H}_{\mathrm{A}}$ : the data do not follow the specified distribution.

The hypothesis regarding the distributional form is rejected at the chosen significance level $(\alpha)$ if the test statistic, D, is greater than the critical value obtained from a table. The fixed values of $(0.01,0.05$ etc. $)$ are generally used to evaluate the null hypothesis $\left(\mathrm{H}_{0}\right)$ at various significance levels. A value of 0.05 is typically used for most applications, however, in some critical industries, a lower value may be applied. The standard tables of critical values used for this test are only valid when
CDF shows probability that for example, voltage will be lower (p.u) than rated voltage $d_{i}$ :

$$
v_{d i} \leq P_{d}\left(d \leq d_{i}\right)
$$

$$
P_{d}\left(d \leq d_{i}\right)=F_{d}\left(d_{i}\right)
$$

According to (8), (9) and (10):

$$
v_{d i}=\int_{0}^{d_{i}} f(d) d d
$$
voltage values with greater p.u values will be in permitted limits (vice versa also applies):

$$
v_{z i}=1-v_{d i}
$$

If $d_{i}$ is the minimum allowed voltage in p.u, it means that all 
Taking in account (8):

$$
v_{z i}=1-P_{d}\left(d \leq d_{i}\right), d_{i} \neq 0
$$

\section{RESULTS}

Results of time series load values of TS A and B (in percentage values), and voltage drop of TS C and D (in p.u values) are given below. For load values of TS A and B, bins are $5 \%$ classes of load values from minimal to maximal percentage load values. For voltage drop of TS C and D bins are 0.01 p.u classes of p.u voltage values from minimal to maximal p.u voltage values. In every case all selected distributions are satisfying fitted according to Kolmogorov-Smirnov test.

Fig. 4. shows PDF of load values in percentage of rated transformer power for TS A. Fig. 5. shows PDF of load values in percentage of rated transformer power for TS B. Fig. 6 . shows PDF of p.u values in percentage of rated voltage (voltage drop) for TS C. Fig. 7. shows PDF of p.u values in percentage of rated voltage (voltage drop) for TS D.

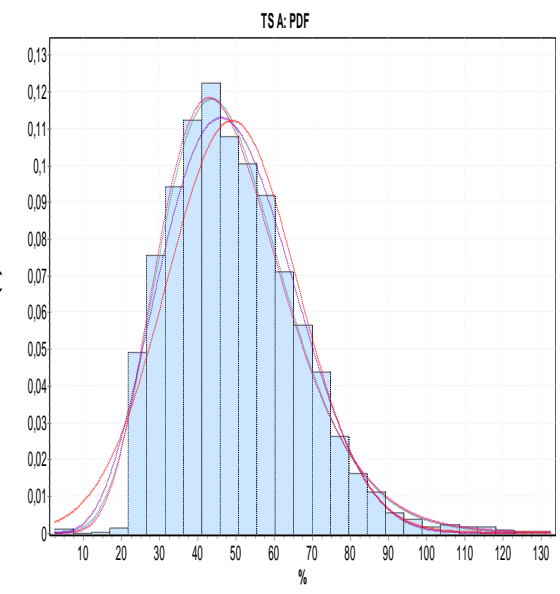

[Histogram - Beta - Ganma - Log.Peason3-Nomal

Fig. 4. PDF of load values in percent of rated transformer power (TS A) [1]

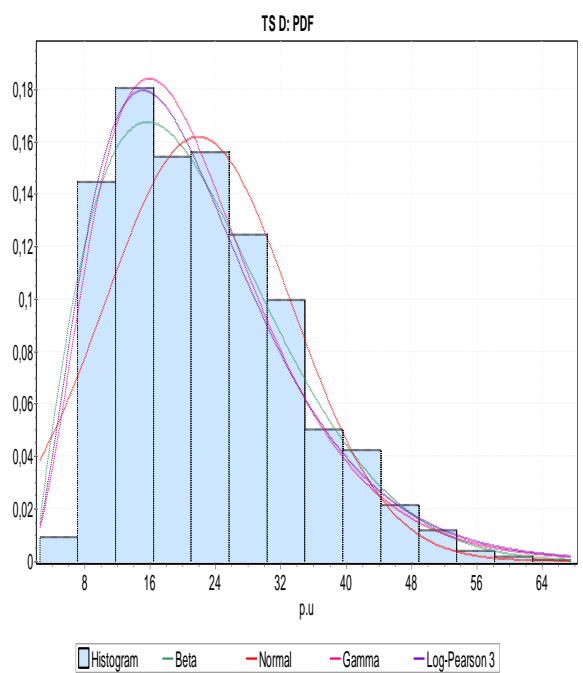

Fig. 5. PDF of load values in percen of rated transformer power (TS B) [1]

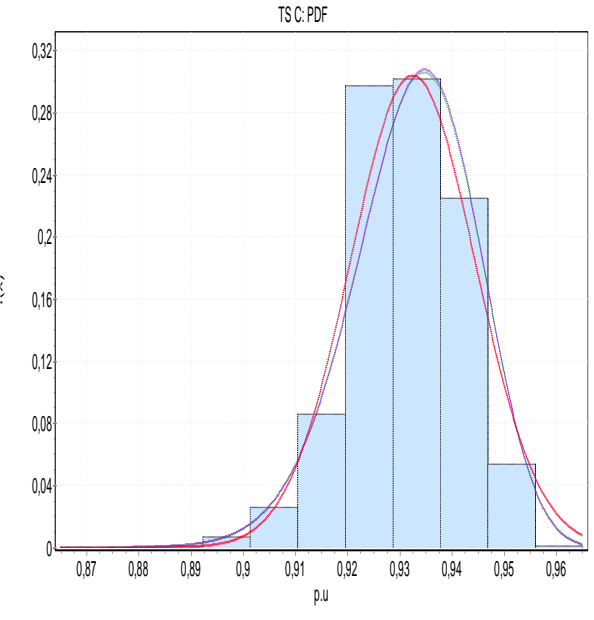

Whistogram - Beta -Gamma -Log-Pearson3-Nomal

Fig. 6. PDF of p.u values in percent of rated voltage (TS C) [1]

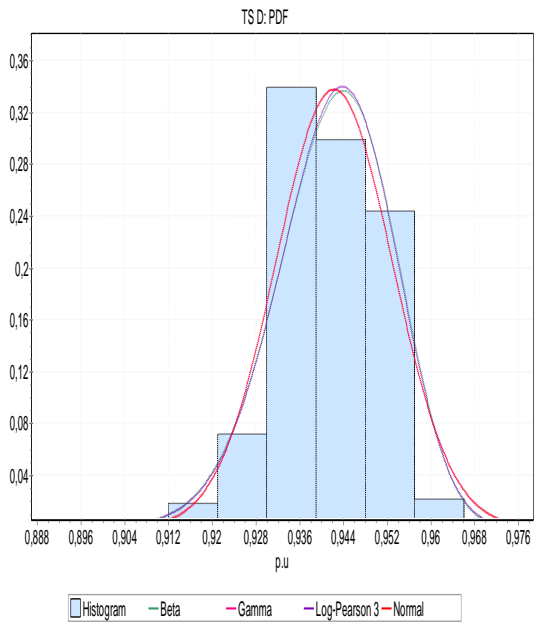

Fig. 7. PDF of p.u values in percent of rated voltage (TS D) [1]

Table IV. presents some analysis of CDF (based on Fig. 3.) of all selected TS (in \% of hours/year). For TS A and B were investigated two cases:

- $\mathrm{P}>\mathrm{P}_{\text {rated, }}$ presents case when transformer power is greater than it's rated power.

- $\quad \mathrm{P}<50 \% \mathrm{P}_{\text {rated, }}$ presents case when transformer power is lower than $50 \%$ of rated power.

- $60 \% \mathrm{P}_{\text {rated }} \leq \mathrm{P} \leq 80 \% \mathrm{P}_{\text {rated }}$, presents load for transformer optimal work.

For TS C and D were investigated two cases:

- $\quad$ p.u<0.92, presents case when voltage drop in p.u is $8 \%$ at LV bus.

- $\quad$ p.u $<0.95$, presents case when voltage drop in p.u is $5 \%$ at LV bus.

In all cases Beta distribution is selected for statistical analysis of transformer power and p.u voltage values.

Beta distribution is chosen only for example - case study. Similar results are with using Normal, Gama and Log-Pearson 3 distributions. 
TABLE IV.

SUMMARY OF RESULTS

\begin{tabular}{lcccc}
\hline \hline \multirow{2}{*}{ Parameter } & \multicolumn{4}{c}{ \% of hours/year } \\
\cline { 2 - 5 } & A & B & C & D \\
\hline $\mathrm{P}>\mathrm{P}_{\text {rated }}$ & 0.66 & 0 & $/$ & $/$ \\
$\mathrm{P}<50 \% \mathrm{P}_{\text {rated }}$ & 56.42 & 98.21 & $/$ & $/$ \\
$60 \% \mathrm{P}_{\text {rated }} \leq \mathrm{P} \leq 80$ & 19.04 & 7.63 & $/$ & $/$ \\
$\% \mathrm{P}_{\text {rated }}$ & $/$ & $/$ & 14.87 & 2.44 \\
p.u $<0.92$ & $/$ & $/$ & 93.92 & 75.40 \\
p.u $<0.95$ & & $/$ & \\
\hline \hline
\end{tabular}

Table V. presents Goodness of Fit results (obtained using EasyFit Software) in terms of K-S values for TS A. It is an example case study (for Beta distribution).

TABLE V.

GOODNESS OF FIT - DETAILS, CASE STUDY EXAMPLE

\begin{tabular}{cccc}
\hline \hline$\alpha$ & P-Value & $\begin{array}{c}\text { Critical } \\
\text { value }\end{array}$ & Reject \\
\hline 0.2 & 0.99688 & 0.2003 & NO \\
0.1 & 0.99688 & 0.2289 & NO \\
0.05 & 0.99688 & 0.2543 & NO \\
0.02 & 0.99688 & 0.2843 & NO \\
0.01 & 0.99688 & 0.3050 & NO \\
\hline \hline
\end{tabular}

For all analyzed cases (TS A-D and for chosen distributions), there was no case of rejection.

\section{DISCUSSION}

Selected TS are quite different in their properties but good fitted with selected distributions in each case. Results obtained by statistical analysis lead to following observations:

- For TS A transformer, max. (peak) power is $32.5 \%$ over rated power (over-loaded state), although mean power of transformer is slight under $50 \%$ of rated power. Transformer overloaded duration time is (only) $0.66 \%$ hours/year. Absence of time series data and existence of only max. power value data could lead owner of transformer on changing transformer with the one with greater rated power. It would not be good solution in this case because it would increase expenses due to new transformer investment and it would increase technical losses. Transformer is loaded in optimal percent around $20 \%$ of year.

- $\quad$ For TS B, transformer is under-loaded (64.25\%), with mean of around $20 \%$ of rated power. For over $98 \%$ of time period of year, transformer power is lower than $50 \%$ of rated power. This transformer can be a good candidate for changing with the one with lower rated power. Transformer is loaded in optimal percent only $7.63 \%$ of year.

- For TS C mean value of voltage is 0.932 p.u. what is not considerable problem. Problem is min. voltage value of 0.865 p.u. what is significant voltage drop and those values deeper in LV grid can be very problematic for power consumers. Statistical analysis shows that almost $15 \%$ of time period of year voltage drop is greater than $8 \%$ (0.92 p.u.) and almost $94 \%$ of time period voltage drop is greater than $5 \%$. This TS is at the end of long radial feeder (overhead line with $\mathrm{Al} / \mathrm{Fe}$ conductors). Consumers from this TS can have potentially voltage drop problems. DSO must consider options for investment/reconstruction in MV grid for improving voltage conditions. These actions may contain changing of existing conductors with the one with greater cross-section. But, optimal tap-changer position can be set on transformer too.

- $\quad$ For TS D mean value of voltage is 0.942 p.u. what is similar as for TS C. Min. voltage value is 0.885 p.u. what is too similar for TS C. But, for TS D "only" $2.44 \%$ of time period of year voltage drop is greater than $8 \%$, and around $15 \%$ of time period of year voltage drop is greater than $5 \%$ That is a great difference comparing with TS $\mathrm{C}$, even mean and minimum value are not very different.

General improvements of using statistics in smart meter data analysis can be observed in following facts (in this case):

- $\quad$ TS C must be priority for improvement of voltage conditions. TS $\mathrm{C}$ and D are both rural TS at the different end side of long radial overhead line. Using statistics and smart meter data, priority for investment can be adopted. This conclusion would be generally hard to make without using statistics in smart meter data analysis. This knowledge can help in making investment/reconstruction plans for utilities.

- Transformer in TS B can be potentially changed or rotated with the one of decreased rated power. Some further analyses should be done for this adoption. But, if it would be possible, technical losses due to transformer can be decreased. For both TS, transformer is majority of year underload.

\section{CONCLUSION}

The goal of this paper was to select statistical distributions to describe the frequency of transformer load values and p.u voltages for selected TS. Several distributions were fitted. Three of them are two-parameter distributions and one is threeparameter distribution. It is shown that all four distributions are good fitted in each case of TS data analysis, regardless different features of TS and different classes of analyzed data ( $\mathrm{P}$, voltage p.u). Kolmogorov-Smirnov test based on CDF is selected as appropriate test because deal was with CDF. It can be concluded that statistical analysis approach proposed here is a very powerful tool for analyzing of great amount of data in distribution grid. This analysis gives very useful and easy $\mathrm{read} /$ understand information. It can be useful in area of distribution grid analysis, planning, maintenance, investment and operation. Also, statistical results can be compared for different areas (urban, rural). Statistical results can help in obtaining time patterns of grid and customers features. Proposed statistical tool is easy applicable for DSO engineers 
and decision makers. Using statistics for smart meter data analyzing, schedule of investment/reconstruction can be adopted. It makes investment/reconstruction plans more meaningful and precisely. This conclusion would be general harder to make without using statistics in smart meter data analysis. This knowledge can help in improving of making investment/reconstruction plans for utilities. In practice, using of proposed statistical approach can decrease expenses for DSO in area of distribution grid reconstruction plans and investments. Further work would consist of analyzing some other distributions and finding best fitting distribution for analyzing different classes of data such voltage, power, current, losses etc. Further, different time period for collecting data of smart meters would be analyzed and compared. This work can be extended for various areas analysis, such feeder, group of feeders, different consumer types, whole areas etc.

\section{ACKNOWLEDGMENT}

This work was supported by JP Elektroprivreda HZHB d.d, Mostar, Bosnia and Herzegovina.

\section{REFERENCES}

[1] I. Ramljak and Drago Bago, "Statistical Approach in Analyzing of Advanced Metering Data in Distribution Grid," in 3th International Multidisciplinary Conference on Computer and Energy Science (SpliTech), Split, Croatia, 2018, pp. 1-6.

[2] D. Scholz and F. Musgens, "How to improve standard load profiles: Updating, regionalization and smart meter data," in Proc. International Conference on the European Energy Market (EEM), Dresden, Germany, 2017, pp. 1-6. DOI: 10.1109/EEM.2017.7981939

[3] N. Lu, P. Du, X. Guo and F.L Greitzer, "Smart meter data analysis," In Proc. IEEE PES Transmission and Distribution Conference and Exposition, Orlando, FL, USA, 2012, pp. 1-6. DOI: 10.1109/TDC.2012.6281612

[4] A. Mutanen, P. Jarventausta, M. Karenlampi and P. Juuti, "Improving distribution network analysis with new AMR-based load profiles," In Proc. CIRED Conference, Stockholm, Sweden, 2013, pp. 1-4. DOI 10.1049/cp.2013.0928

[5] T.J. Morrell, V. Venkataramanan, A. Srivastava, A. Bose and C.C Liu, "Modeling of Electric Distribution Feeder Using Smart Meter Data," In Proc. IEEE/PES Transmission and Distribution Conference and Exposition, Denver, CO, USA, 2018, pp. 1-5. DOI 10.1109/TDC.2018.8440540

[6] X. Liu and P. S. Nielsen, "Streamlining smart meter data analytics," in Proc. SDEWES, Dubrovnik, Croatia, 2015, pp. 1-13

[7] X. Liu, L. Golab, W. Golab and F. Ilyas, "Benchmarking smart meter data analytics," in Proc. EDBT, Brussels, Belgium, 2015, pp. 385-396. DOI 10.5441/002/edbt.2015.34

[8] X. Liu, L. Golab and F. Ilyas, "SMAS: A smart meter data analytics," in Proc. ICDE, Seoul, South Korea, 2015, pp. 1-4. DOI 10.1109/ICDE.2015.7113405

[9] U. Singh, V. Zamani and M. Baran, "On-line load estimation for distribution automation using AMI data," in Proc. PESGM, Boston, MA, USA, 2016, pp.1-5. DOI: 10.1109/PESGM.2016.7741806

[10] V. Ford and A. Siraj, "Clustering of smart meter data for disaggregation," in Proc. GlobalSIP, Austin, TX, USA, 2013, pp. 1-4. DOI: 10.1109/GlobalSIP.2013.6736926

[11] A. Tureczek, P. S. Nielsen and H. Madsen, "Electricity consumption clustering using smart meter data," Energies, vol. 11, no. 4, pp. 1-18, April, 2018. DOI: 10.3390/en11040859

[12] E. Carpaneto, G. Chicco, R. Porumb and E. Roggero, "Probabilistic representation of the distribution system restoration times," in. Proc CIRED, Torino, Italy, 2005, pp. 1-5. DOI: 10.1049/cp:20051071

[13] M. Edimu, C.T. Gaunt and R. Herman, "Using probability distribution functions in reliability analyses," Electric Power System Research, vol 81, no. 4, pp. 915-921, April, 2011. DOI: 10.1016/j.epsr.2010.11.022
[14] E. Carpaneto and G. Chicco, "Probability distributions of the aggregated residential load," in Proc. PMAPS, Stockholm, Sweden, 2006, pp. 1-6. DOI: 10.1109/PMAPS.2006.360235

[15] A. Navarro-Espinoza, T. Gozel, L.F. Ochoa, R. Shaw and D. Randles, "Data analysis of LV networks: key parameters from one year of monitoring over hundreds UK LV feeders," in. Proc. CIRED, Lyon, France, 2015, pp. 1-5.

[16] N. Cross, R. Herman and C.T. Gaunt, "Investigating the usefulness of the Beta pdf to describe parameters in reliability analyses," in Proc. PMAPS, Stockholm, Sweden, 2006, pp. 1-6. DOI: 10.1109/PMAPS.2006.360299

[17] I. Ramljak, M. Majstrović and Elis Sutlović, "Statistical analysis of particles of conductor clashing," in Proc. Energycon, Dubrovnik, Croatia, 2014, pp. 671-676. DOI: 10.1109/ENERGYCON.2014.6850494

[18] M.E de Oliveira, D.F.A. Boson and A. Padilha-Feltrin, "A statistical analysis of loss factor to determine the energy losses," in Proc. IEEE/PES Transmission and Distribution Conference and Exposition, Bogota, Columbia, 2008, pp. 1-6. DOI: 10.1109/TDC-LA.2008.4641691

[19] "EasyFit Software," 2013., MathWave Technologies.

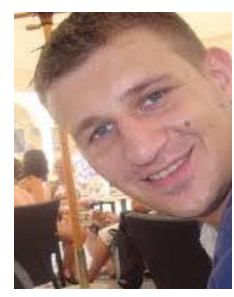

Ivan Ramljak was born in Mostar (Bosnia and Herzegovina) in 1985. He graduated in 2009 and got his $\mathrm{PhD}$ degree in 2016 in Electrical engineering (area of power systems), both at University of Split (Faculty of Electrical engineering, Mechanical engineering and Naval architecture, Croatia). Since 2009, he has been employed by the Public Electric Utility "Elektroprivreda HZ HB" Mostar and since 2018 at the University of Mostar, Faculty of Mechanical Engineering, Computing and Electrical Engineering as an Assistant professor. Area of his interests include power system analysis, power system protection, grounding systems, renewable energy sources and economics in engineering. He is the author of more than 30 research and professional papers in area of power engineering. $\mathrm{He}$ is an IEEE PES member and CIGRE member in B\&H section and member of CIGRE Paris. He is also a secretary of B\&H CIRED section. Since 2016 he is a certified engineer in $\mathrm{BiH}$

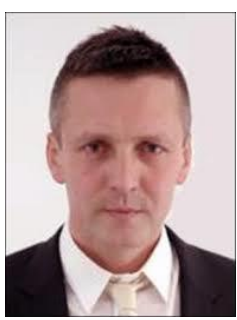

Drago Bago graduated and completed postgraduate $\mathrm{PhD}$ study at the Faculty of Electrical Engineering and Computing, University of Zagreb. Since 2000 he has been employed at the JP "Elektroprivreda HZ HB" d.d. Mostar in Distribution Power Division and Development Division. At the moment, he is the member of the Board and Executive Director for Development in JP "Elektroprivreda HZ HB" d.d. Mostar. He completed a professional study 'Energy Efficiency" organized by the Institute of Energy Technology in Kjeller (Oslo), Norway and the Faculty of Electrical Engineering and Computing. He is the author or co-author of several scientific and professional papers in the field of overvoltage protection for medium voltage lines, the correlation of events data from the power system and data from the system of Lightning Location System, energy efficiency and the field of supervisory, control and data acquisition in the medium voltage power system. $\mathrm{He}$ is a member of the international professional organization IEEE. He is also a member of the Study Committee of the International Council on Large Electric Systems CIGRÉ in Paris, Study Committee C6 - Distribution Systems and Dispersed Generation. He is the President of the International Conference of CIRED for Bosnia and Herzegovina and President of the Study Committee C6 BH K CIGRÉ - Distribution Systems and Dispersed Generation. He is a member of the Board of BH K CIGRÉ. He is a member of the Board BAKE BH Council for Electrical Engineering. He is a member of the Editorial Council of the magazine "BH Elektrotehnika". He is a member of the Croatian Association of Engineers - AMAC. 